6

7 a The Institute of Seawater Desalination and Multipurpose Utilization, SOA (Tianjin),

$12 *$ Corresponding Author E-mail: sandraek@unimelb.edu.au (S. E. Kentish).

3

4 Qiang Li, ${ }^{\mathrm{a}}$ George Q. Chen, ${ }^{\mathrm{b}}$ Liang Liu, ${ }^{\mathrm{b}}$ and Sandra E. Kentish ${ }^{* \mathrm{~b}}$

5

8

8
Tianjin 300192, China

b Department of Chemical Engineering, The University of Melbourne, VIC 3010,

Australia

1

.

3

14 


\section{Abstract}

16 A single-bilayer polyelectrolyte reverse osmosis membrane was fabricated by a spray 17 assisted layer-by-layer assembly approach using a polysulfone ultrafiltration membrane as 18 a substrate, polyethyleneimine (PEI) as an adhesion promoter, poly(allylamine 19 hydrochloride) (PAH) and poly(sodium-4-styrene sulfonate) (PSS) as polycation and 20 polyanion, glutaraldehyde as a crosslinker and Pluronic F127 amphiphilic triblock 21 copolymer as a surface modifier. The resulting active layer is ultrathin $(\mathrm{ca} .70 \mathrm{~nm})$ and has

22 a flat, dense and uncharged surface in neutral solution. The salt rejection and permeate flux 23 of the membrane gradually increases from $92 \%$ to $94 \%$, and $11 \mathrm{~L} / \mathrm{m}^{2} \mathrm{~h}$ to $30 \mathrm{~L} / \mathrm{m}^{2} \mathrm{~h}$ 24 respectively for a $2 \mathrm{~g} / \mathrm{L} \mathrm{NaCl}$ feed solution as the operating pressure increased from 1.6 $25 \mathrm{MPa}$ to 4.0 MPa. Additionally, the membrane shows good separation performance stability 26 and protein fouling resistance using bovine serum albumin as a foulant model. The 27 glutaradehyde plays a key role in enhancing salt rejection by forming imine bonds within 28 the PEI layer and the PEI/PAH interlayer. The Pluronic F127 surface modifier improves 29 the permeate flux due to its hydrophilicity and the resulting induced swelling providing 30 channels for water flow. Further, the "brush-like" structure of the hydrophilic polyethylene 31 oxide moieties on the membrane surface improves fouling resistance. 


\section{Introduction}

34 The scarcity of fresh water is an increasingly serious global issue, due to population 35 expansion, climate change, and environmental pollution [1,2]. To increase global fresh 36 water reserves, reverse osmosis (RO) desalination is increasingly employed owing to its 37 low energy consumption, low cost, and ease of operability [3,4]. While commercial RO membranes are formed by interfacial polymerization, layer-by-layer (LBL) assembly has emerged as a useful alternative approach $[5,6]$ due to its simplicity and the use of aqueous solutions [7-9]. The process classically involves dipping the substrate in solutions of differently charged polyelectrolytes in turn, with intermediate rinsing steps. In comparison with the traditional interfacial polymerization approach, a wide range of molecules can be deposited via interlayer interactions such as electrostatics [10], hydrogen bonding [11], metal-ligand coordination [12] and covalent bonding [13]. The technique can provide precise control of hydrophilicity, surface charge and membrane thickness at the nanoscale.

LBL assembled membranes have mainly been developed for nanofiltration $[14,15]$ and the approach has also been used in pervaporation, and forward osmosis $[16,17]$. These membranes usually have low $\mathrm{NaCl}$ rejection $(<80 \%)$, due to poor membrane densification and the swelling of the polyelectrolytes in aqueous solution [18-20]. For example, Grooth et al [19] fabricated a 7-bilayer polyelectrolyte membrane by alternatively depositing poly(diallyldimethylammonium chloride) (PDADAMAC) and poly(sodium-4-styrene sulfonate) (PSS) on a sulfonated poly(ether sulfone) based ultrafiltration membrane using dipping. This membrane shows $71 \%$ and $96 \%$ rejection for $0.5 \mathrm{M} \mathrm{NaCl}$ and $\mathrm{Na}_{2} \mathrm{SO}_{4}$ aqueous solutions respectively. Covalent cross-linking between the deposited layers has been used to further increase the density of the membrane [21-23]. Park et al [21] reported

57 (PAA) polyelectrolyte membrane with 10 bilayers and $250 \mathrm{~nm}$ active-layer thickness 
fabricated by dipping LBL assembly. This membrane exhibits high $\mathrm{NaCl}$ rejection $(99.8$ \%) but low permeate flux $\left(8 \mathrm{~L} / \mathrm{m}^{2} \mathrm{~h}\right)$ under $2 \mathrm{MPa}$ pressure for $2 \mathrm{~g} / \mathrm{L} \mathrm{NaCl}$ feed solutions.

60 The classical dipping LBL assembly approach usually take a few hours to several days 61 to deposit sufficient bilayers to ensure a defect-free, dense structure [24,25]. Spray LBL 62 assembly, as proposed by Schlenoff et al in 2000 [26] decreases the membrane fabrication 63 time. This method can be used to spray polyelectrolytes onto any solvent-accessible two 64 dimensional and/or three dimensional substrate [24,27]. For example, our group fabricated 65 a glutaradehyde (GA) crosslinked polyelectrolyte RO membrane by spraying 10 bilayers 66 of PAH and PSS onto a polysulfone (PSF) substrate [28]. The membrane possessed high $67 \mathrm{NaCl}$ rejection $(90 \%$ ) for $2 \mathrm{~g} / \mathrm{L} \mathrm{NaCl}$ feed solution at $2.4 \mathrm{MPa}$ operating pressure. 68 However, it also showed low permeate flux $\left(8 \mathrm{~L} / \mathrm{m}^{2} \mathrm{~h}\right)$. This is because the high bilayer 69 number, coupled with the glutaraldehyde crosslinking, resulted in a thick, dense membrane 70 active layer. Further, the need for multiple bilayers still leads to a protracted manufacturing 71 operation. The fabrication of a single bilayer RO membrane of comparable rejection but 72 higher flux would facilitate production at a larger scale.

73 Surface modification using hydrophilic chemicals and/or nanostructured materials is a 74 common strategy for optimizing the permeate flux and fouling resistance of water 75 treatment membranes fabricated by interfacial polymerization and phase inversion 76 approaches [29-31]. Pluronic F127 $\left(\mathrm{PEO}_{106}-\mathrm{PPO}_{70}-\mathrm{PEO}_{106}\right)$ is a triblock copolymer 77 composed of two hydrophilic polyethylene oxide (PEO) chains surrounding a central 78 hydrophobic polypropylene oxide (PPO) chain. It is often anchored onto the membrane 79 surface to increase the hydrophilicity and fouling resistance [31-34]. The PEO segments 80 can form "brush-like" structures on the surface after the polymer is swollen in aqueous 81 solution [33]. For example, Falath et al fabricated a Pluronic F127 modified bisphenol A 82 diglycidyl ether crosslinked Poly (vinyl alcohol) (PVA)/ gum Arabic RO membrane by a 
83 dissolution casting solution method [34]. This research suggests that this modifier could be

84 an effective way to optimize the hydrophilicity and separation performance of LBL

85 membranes. However, to our knowledge, there have been no reports to date involving

86 surface modification of LBL membranes using such a non charged polymer.

87 Herein we fabricate a GA crosslinked 1-bilayer polyelectrolyte membrane modified by 88 Pluronic F127 via spray LBL assembly. A polysulfone ultrafiltration membrane is used as 89 a substrate, PEI as an adhesion promoter, PAH and PSS as polycation and polyanion 90 respectively. The salt rejection and permeate flux of this PEC membrane can reach up to $9194 \%$, and $30 \mathrm{~L} / \mathrm{m}^{2} \mathrm{~h}$ respectively under $4.0 \mathrm{MPa}$ operating pressure for a $2 \mathrm{~g} / \mathrm{L} \mathrm{NaCl}$ 92 aqueous solution. Importantly, the use of a single bilayer leads to a facile manufacturing 93 technique that has great prospects for large-scale desalination operations.

\section{2. Materials and Methods}

95 104 Solutions.

\subsection{Chemicals and materials}

Branched polyethylenimine (PEI, Mw 25,000), poly(sodium-4-styrene sulfonate) (PSS, $\mathrm{Mw} \sim 70,000)$, glutaraldehyde (GA, $25 \mathrm{wt} \%$ solution in water), Pluronic F127 $\left(\mathrm{PEO}_{106}\right.$ $\mathrm{PPO}_{70}-\mathrm{PEO}_{106}, \mathrm{M}_{\mathrm{w}} \sim 12,600$ ), and bovine serum albumin (BSA) were purchased from Sigma-Aldrich. Poly(allylamine hydrochloride) (PAH, Mw 120,000 to 200,000) was obtained from Alfa Aesar. Sodium chloride, boric acid, potassium chloride, sodium hydroxide, and hydrochloric acid were purchased from Chem-Supply. The polysulfone (PSF) ultrafiltration substrate (MWCO $\sim 92.5 \mathrm{kDa}, \mathrm{A} 1)$ was kindly provided by GE Water. A commercial SW30 HR RO membrane was purchased from Dow Water and Process 


\subsection{Polyelectrolyte membrane fabrication}

107 To prepare a one-bilayer membrane, the PSF substrate $\left(c a .10 \times 10 \mathrm{~cm}^{2}\right)$ was fixed to a hard 108 plastic sheet which was held vertically. A gravity fed pressure spray gun (Austech 109 Industries, Australia) was used to deliver each solution to the membrane. The gun reservoir 110 was pressured with nitrogen at around 3.5 Bar to create a mist spray, with the distance 111 between the substrate and nozzle of the sprayer around $20 \mathrm{~cm}$. Initially, $8 \mathrm{ml}$ of PEI aqueous 112 solution $(5 \mathrm{~g} / \mathrm{L})$ was sprayed as a primer layer. Then $8 \mathrm{ml}$ of GA aqueous solution $(0.1$ $113 \mathrm{~mol} / \mathrm{L}$ ) was sprayed as a cross linker. Subsequently, PSS aqueous solution (5 g/L), and $114 \mathrm{PAH}$ aqueous solution $(5 \mathrm{~g} / \mathrm{L})$ were sequentially sprayed with the same volume to form 115 one electrolyte bilayer. F127 aqueous solution (5 g/L) was sprayed onto the resulting 116 membrane as a surface modifier. The final membrane (referred to as $117 \mathrm{PEI} / \mathrm{GA} / \mathrm{PSS} / \mathrm{PAH} / \mathrm{F} 127$ ) was dried in air at room temperature for at least $3 \mathrm{~h}$ to allow 118 further crosslinking to occur. The time of each spraying step was $10 \mathrm{~min}$. After each step 119 except the GA spraying step, the substrate was rinsed by spraying purified water (MilliQ, 120 Millipore) for $15 \mathrm{~s}$ to remove unabsorbed electrolytes.

121 To investigate the effect of the F127 modifier, membranes were also manufactured 122 without this spray step (referred to as PEI/GA/PSS/PAH) as a control. An uncrosslinked 123 membrane (referred to as $\mathrm{PEI} / \mathrm{PSS} / \mathrm{PAH}$ ) was also fabricated as an additional control 124 sample, where both the GA and F127 spray steps were omitted. Additionally, to explore 125 the separation performance of the PEI primer layer, a membrane coated only with PEI and 126 GA (referred to as PEI/GA) was fabricated. 


\section{.3. Surface property and structure characterization}

130 The membrane surface functional groups were characterized using FTS 7000 Fourier

131 transform infared (IR) spectrometer (Varian, USA) equipped with an attenuated total 132 reflectance (ATR) accessory. A Surpass zeta potential analyser (Anton Paar, Austria) was

133 employed to measure the surface charge properties using $1 \mathrm{mM}$ potassium chloride 134 aqueous solution as electrolyte. The membrane surface was also investigated using Quanta $135200 \mathrm{~F}$ (FEI, USA) scanning electron microscopy (SEM) and the contact angle was obtained 136 on an OCA 20 tensiometer (Dataphysics, USA) using purified water as a measurement 137 solution.

\subsection{Separation performance and stability evaluation}

$1392 \mathrm{~g} / \mathrm{L}$ of $\mathrm{NaCl}$ aqueous solution was used as feed solution to evaluate the rejection and 140 permeate flux of the membranes using a crossflow rig consisting of three parallel CF042 141 cells (Sterlitech, USA) with $c a .42 \mathrm{~cm}^{2}$ active membrane area under various testing 142 pressure (1.6-4.0 MPa). Before collecting the permeate sample, all the membranes were 143 compacted for $2 \mathrm{~h}$ under the test pressure. The salt rejection was calculated by conductivity 144 measurement. The permeate flux was calculated based on the mass of permeate collected 145 over time recorded by an Ohaus Pioneer balance. The separation performance of the 146 commercial SW30 HR RO membrane was also evaluated using the same approach for 147 comparison.

148 To evaluate the stability of the separation performance, the PEI/GA/PSS/PAH/F127 149 membrane was continuously tested for $32 \mathrm{~h}$ under $2.4 \mathrm{MPa}$ pressure using $2 \mathrm{~g} / \mathrm{L} \mathrm{NaCl}$ feed 150 solution by crossflow filtration as described above. The permeate was collected every $2 \mathrm{~h}$ 151 for measuring the salt rejection and permeate flux. 
To further investigate the desalination mechanism, the rejection of boron was also 153 determined via a dead-end filtration cell (Sterlitech HP4750) under 2.4 MPa pressure 154 respectively using $c a .20 \mathrm{mg} / \mathrm{L}$ boron aqueous solution with $\mathrm{pH}=4.0$ and 11 as feed. Before 155 the rejection test, the membrane was compacted using purified water (MilliQ, Millipore) 156 under the same pressure for $2 \mathrm{~h}$. The salt rejection was calculated by measuring the 157 concentrations of boron in the feed solution and permeate using Inductively Coupled 158 Plasma Optical Emission Spectrometry (Varian ICPOES 720 ES).

\subsection{Fouling resistance evaluation}

$1601 \mathrm{~g} / \mathrm{L}$ BSA aqueous solution was employed as a model foulant to evaluate the fouling 161 resistance of the membranes using the dead-end filtration cell mentioned above under 2.4 $162 \mathrm{MPa}$ operating pressure. In each cycle, the BSA solution was filtered for $8 \mathrm{~h}$. The filtration 163 cell was then opened and the membrane flushed with purified water (MilliQ, Millipore) at 164 least 5 times (ca. $30 \mathrm{~s}$ each time). This cycle of fouling and cleaning was repeated three 165 times. Before the evaluation, the membrane was firstly compacted using purified water 166 under the same pressure for $2 \mathrm{~h}$. The permeate was collected every $2 \mathrm{~h}$ to determine the 167 flux. The normalized permeate flux as indicated by the ratio of the flux $(\mathrm{J})$ to the initial 168 flux $\left(\mathrm{J}_{0}\right)$ was utilized to evaluate the fouling resistance.

\section{Results and discussion}

\subsection{Membrane surface properties}

172 The ATR-IR spectra (Fig. 1) show that the IR absorption signal of the PSF substrate is very

173 strong. The IR spectrum of the uncrosslinked PEI/PSS/PAH membrane (Fig. 1b) is nearly 174 identical to that of the PSF substrate (Fig. 1a). In contrast, the crosslinked 
PEI/GA/PSS/PAH membrane (Fig. 1c) shows a broad peak at $3440 \mathrm{~cm}^{-1}$ attributed to the

176 amine-group $(\mathrm{N}-\mathrm{H})$ stretching vibration of the deposited PAH and PEI. Another small peak

177 at $1640 \mathrm{~cm}^{-1}$ can be assigned to the stretching of the imine $(-\mathrm{C}=\mathrm{N}-)$ groups [28]. After

178 Pluronic F127 is sprayed (Fig. 1d), the broad peak of the modified one-bilayer $179 \mathrm{PEI} / \mathrm{GA} / \mathrm{PSS} / \mathrm{PAH} / \mathrm{F} 127$ membrane at $3440 \mathrm{~cm}^{-1}$ becomes more well resolved due to the 180 presence of the hydroxyl groups $(\mathrm{O}-\mathrm{H})$ of the $\mathrm{F} 127$ modifier on the membrane surface. 181 Moreover, the peak related to the imine groups can be still observed in this membrane.

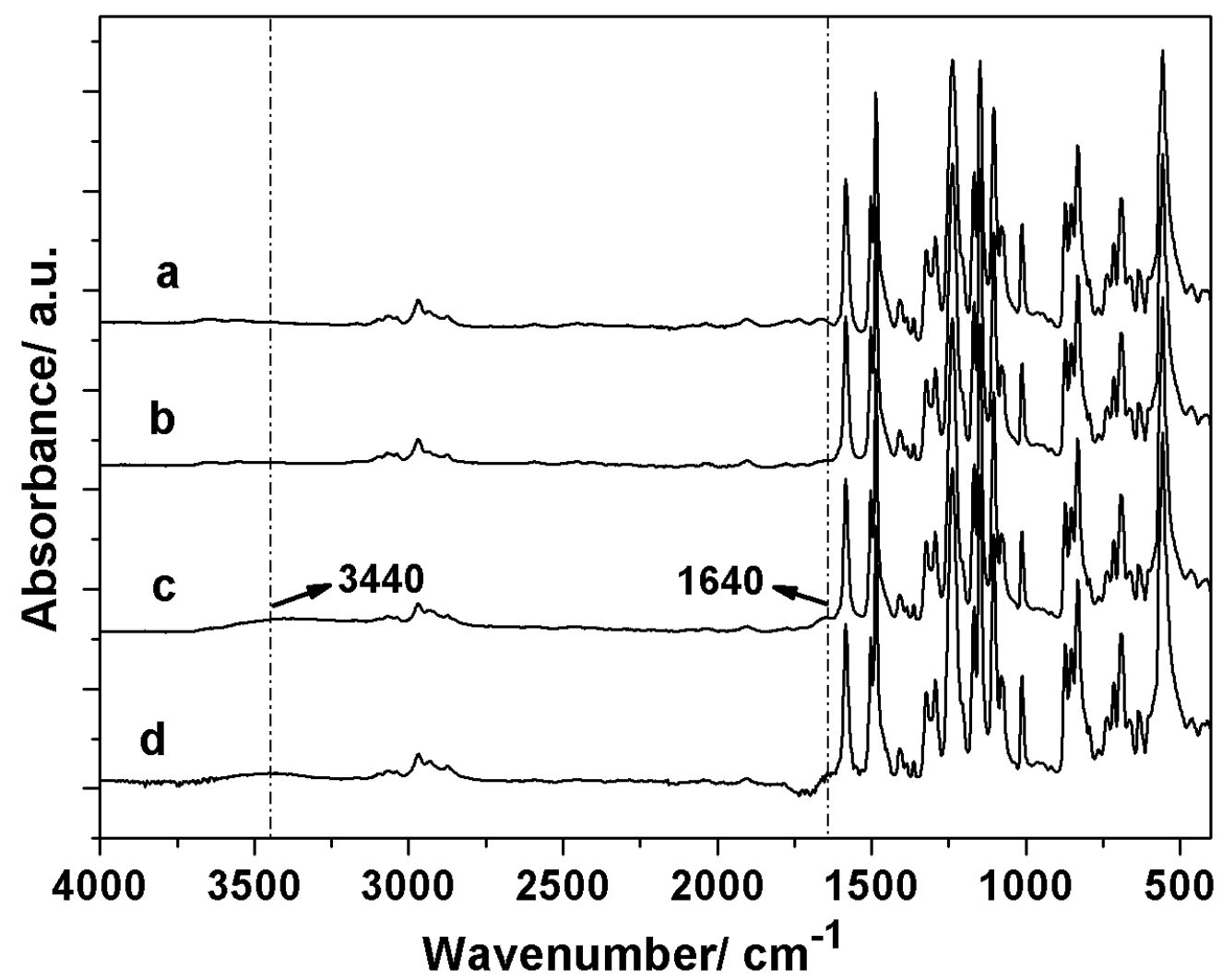

183 Fig. 1. ATR-IR spectra of (a) polysulfone substrate, (b) the uncrosslinked PEI/PSS/PAH 184 membrane, (c) the crosslinked PEI/GA/PSS/PAH membrane, and (d) the F127 modified 185 $\mathrm{PEI} / \mathrm{GA} / \mathrm{PSS} / \mathrm{PAH} / \mathrm{F} 127$ membrane. 
187 These results indicate that there is very little polyelectrolyte absorbed on the substrate 188 for the uncrosslinked PEI/PSS/PAH system (Fig. 1b). After GA is introduced during the 189 membrane fabrication (PEI/GA/PSS/PAH), more PAH polyelectrolytes are anchored onto 190 the substrate due to the formation of the imine bond $(-\mathrm{C}=\mathrm{N}-)$ (Fig. 1c,d) between GA and 191 the amine group containing polyelectrolytes (PEI and PAH).

192 From the zeta potential results (Fig. 2), it can be observed that after the polycation PEI 193 was sprayed (Fig. 2a1), the substrate surface is positively charged in the whole of the $\mathrm{pH}$ 194 measurement range (3.0-9.5). However, the addition of GA reduces the charge and an 195 isoelectric point (IEP) appears at $c a$. $\mathrm{pH} 7.05$ (Fig. 2a2). Subsequently, after the polyanion 196 PSS was sprayed (PEI/GA/PSS), the substrate is negatively charged across the measured $197 \mathrm{pH}$ range (Fig. 2a3). The one-bilayer PEI/GA/PSS/PAH membrane fabricated by 198 subsequently spraying a layer of polycation PAH reduces the negative surface charge with 199 an IEP of pH 5.6 (Fig. 2b3). After the uncharged F127 modifier was further sprayed on to 200 the membrane surface, the IEP increases again to $\mathrm{pH} 7.07$ (Fig. 2b2). The surface of the 201 uncrosslinked PEI/PSS/PAH membrane is positively charged with IEP of pH 9.40 (Fig. 202 2b1), consistent with our prior work $[23,28]$. 

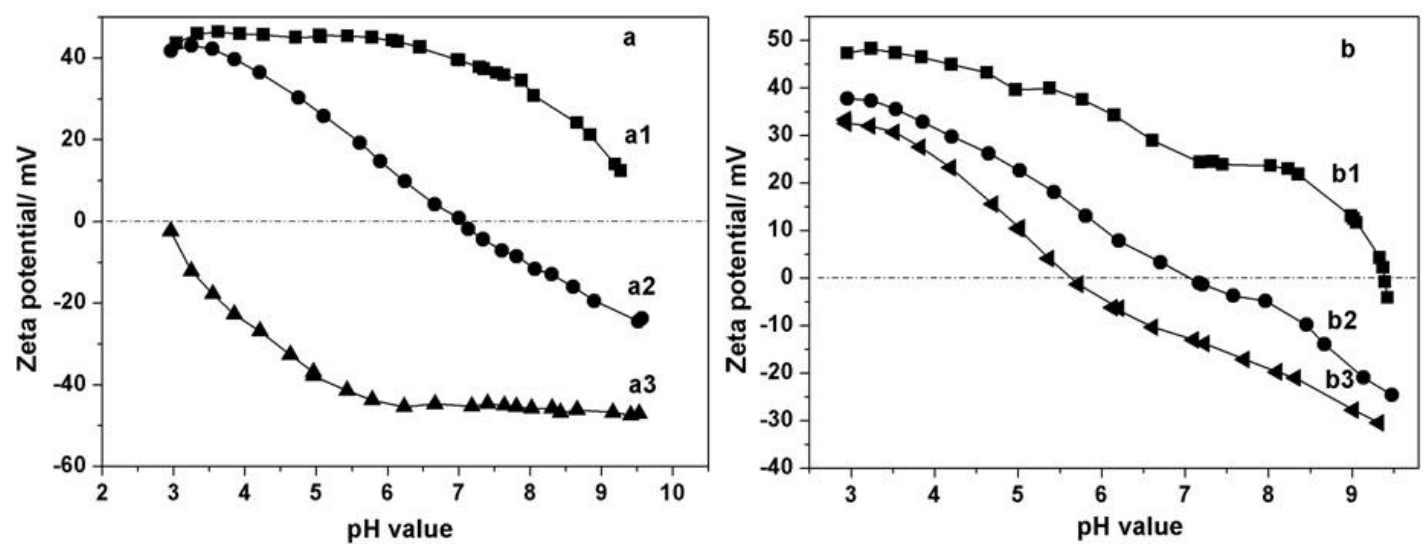

206 Fig. 2. Zeta potential curves of the various polyelectrolyte membranes. (a1) the PSF substrate sprayed with PEI, (a2) the PSF substrate sprayed with PEI/GA, and (a3) the PSF substrate sprayed with PEI/GA/PSS; (b1) the uncrosslinked PEI/PSS/PAH membrane, (b2) the F127 modified PEI/GA/PSS/PAH/F127, and (b3) the PEI/GA/PSS/PAH membrane.

The significant changes in zeta potential after each spraying step (Fig. 2a,b) illustrates that all the sprayed chemicals (polyelectrolytes, crosslinker, and modifier) were successfully sequentially adsorbed on the substrate surface. As described in Scheme 1, the positively charged PEI layer is firstly deposited on the PSF substrate by electrostatic interaction. After GA was subsequently sprayed on to the substrate, it was partly anchored on the PEI-layer surface by the formation of imine bonds $(-\mathrm{C}=\mathrm{N}-)$ as mentioned above.

217 Furthermore, the crosslinking reaction also occurred in the inner of the PEI layer. As a 218 result, the positive charge density of the substrate with PEI/GA layer is drastically 219 decreased due to the decrease of the amine groups of PEI layer, and the IEP 220 correspondingly shifts down to $\mathrm{pH} 7.05$ (Fig. 2a2). When the polyanion PSS was further 221 sprayed, a negatively charged PSS layer is formed by the electrostatic interaction with the 222 slightly positively charged PEI/GA layer. The amine groups of the subsequently sprayed 223 PAH layer can react with the unreacted aldehyde groups of the GA to form more imine 
224 bonds $(-\mathrm{C}=\mathrm{N}-)$. The conversion of the primary amine $(\mathrm{pKa}=9)$ into imine $(\mathrm{pKa}=4)$ results 225 in the formation of the negatively charged surface of the PEI/GA/PSS/PAH membrane 226 (Fig. 2b3) at neutral pH.

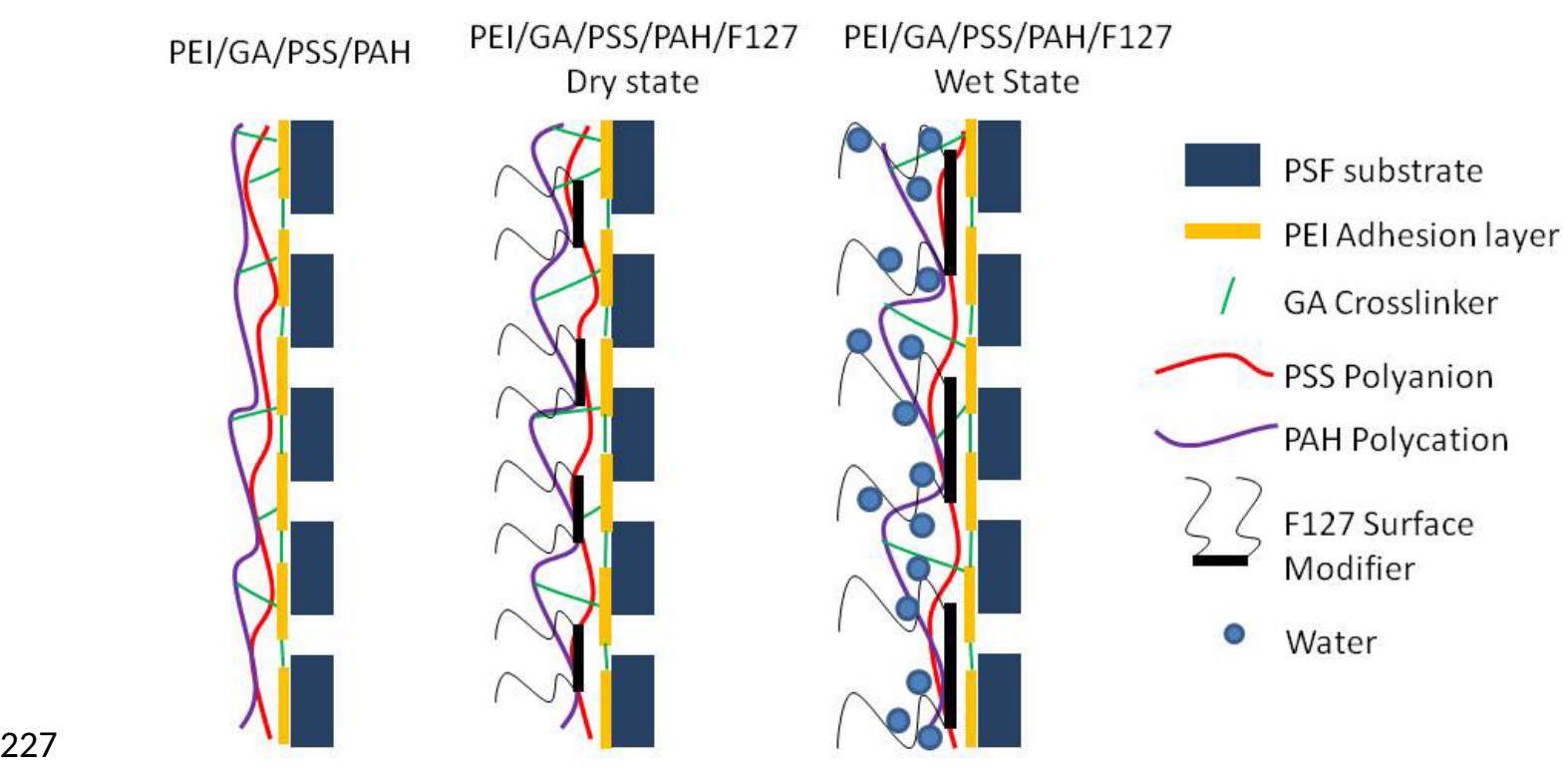

228 Scheme 1. A schematic illustration of the formation of the crosslinked polyelectrolyte membranes and the structural changes that occur when swollen in water.

Significantly, when the F127 is added, the membrane becomes more positively charged across the full $\mathrm{pH}$ range (Fig. 2b2). This suggests that rather than deposition as a surface coating, the central hydrophobic chain within the F127 is penetrating into the LBL structure and driving the positively charged PAH amine groups closer to the surface. The results illustrate that the crosslinker GA and modifier F127 have an important influence on the surface charge properties and structure of the membranes. 
$239\left(71^{\circ} \pm 2\right)$, indicating that the former is more hydrophilic than the latter due to the presence 240 of hydroxyl $(-\mathrm{OH})$ and ether $\left(-\mathrm{CH}_{2}-\mathrm{O}-\mathrm{CH}_{2}-\right)$ groups within the $\mathrm{F} 127$ polymer.

\section{3.2. Membrane structure and morphology}

242 Some mesopores $(c a .10-20 \mathrm{~nm})$ are clearly visible in the SEM image of the PSF 243 substrate (Fig. 3a, also shown as a larger image in the Supporting Information Fig. S1).

244 The uncrosslinked PEI/PSS/PAH membrane (Fig. 3d and Fig. S4) also appears to show 245 small mesopores. This suggests that very little polyelectrolyte has been deposited on the 246 substrate, which is consistent with the ATR-IR results (Fig. 1). In contrast, the surface of 247 the crosslinked and F127 modified one-bilayer membranes (Fig. 3b and c, also shown as 248 Fig. S2 and S3) become denser and more uniform, indicating a greater surface 249 coverage.The uniform thickness and smooth cross section can be clearly observed after 250 spray LBL in the cross-sectional images (Fig. 4b and c, also shown as Fig. S5 and S6). The 251 thickness of the combined PEI/GA/PSS/PAH layers (Fig. 4b) is $c a .50 \mathrm{~nm}$. After F127 was 252 sprayed, the thickness of the combined layers (Fig. 4c) slightly increases to $c a .70 \mathrm{~nm}$. 


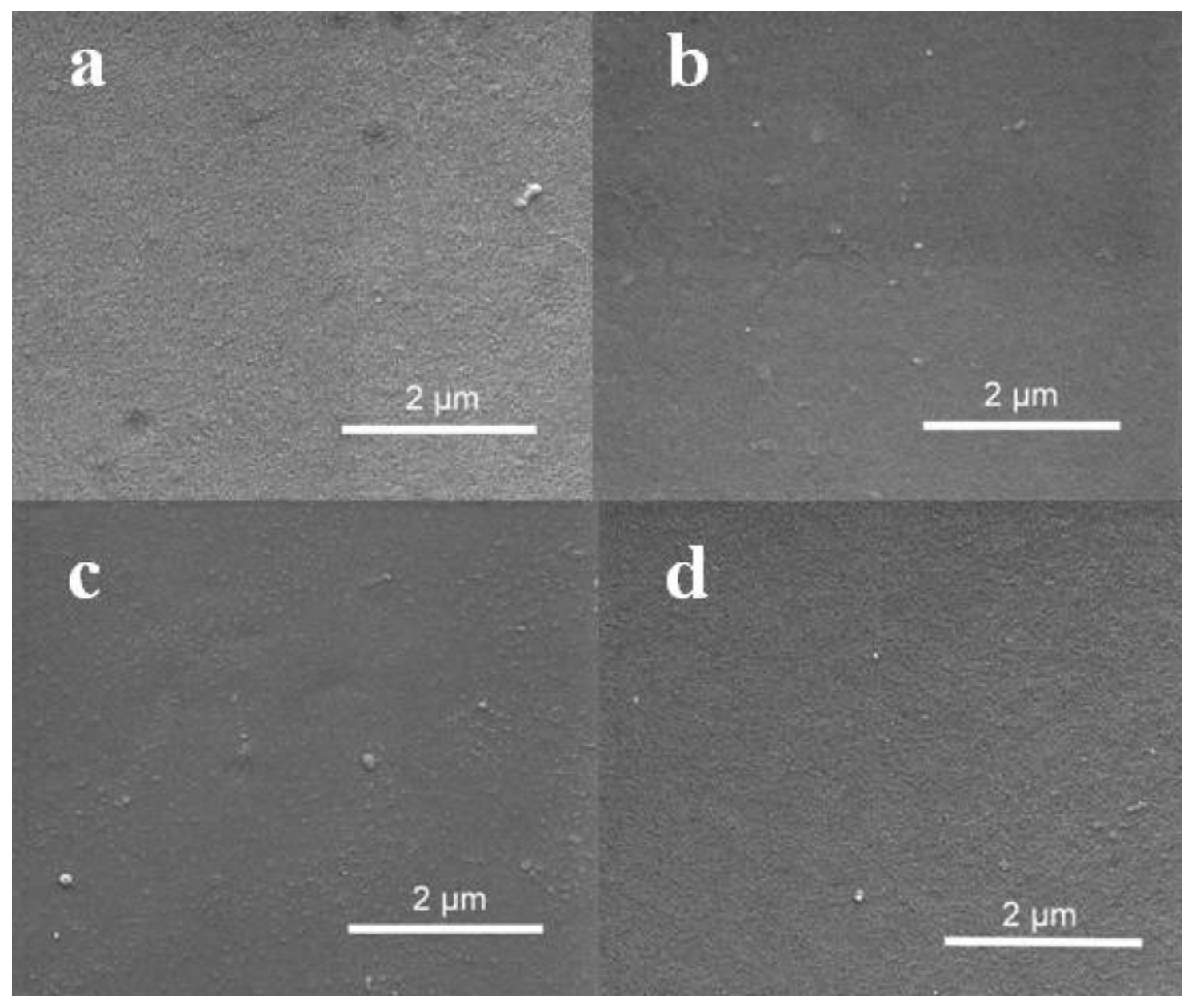

256 Fig. 3. SEM images of the top surfaces of the (a) PSF substrate; (b) the modified $257 \mathrm{PEI} / \mathrm{GA} / \mathrm{PSS} / \mathrm{PAH} / \mathrm{F} 127$ membrane; (c) the unmodified PEI/GA/PSS/PAH membrane and 258 (d) the uncrosslinked PEI/PSS/PAH membrane. 

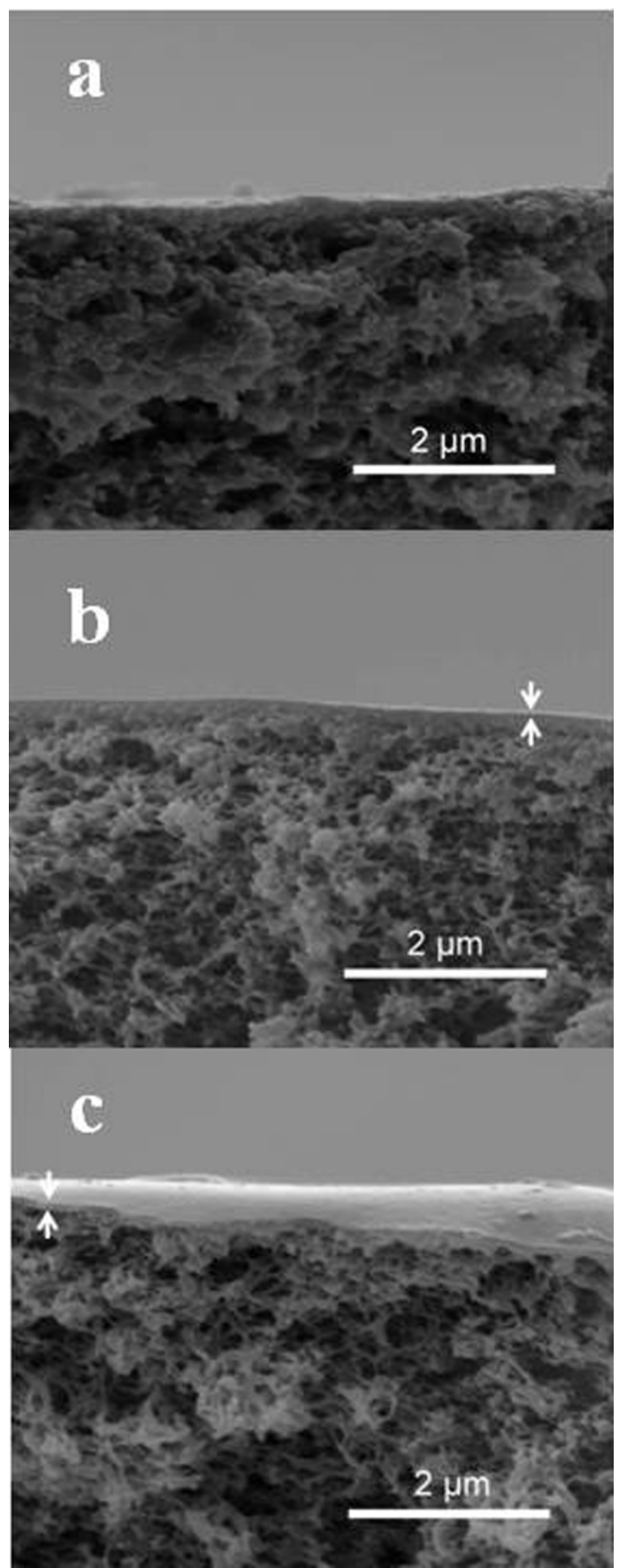

260 Fig. 4. SEM images of the cross sections of (a) PSF substrate, (b) the unmodified $261 \mathrm{PEI} / \mathrm{GA} / \mathrm{PSS} / \mathrm{PAH}$ membrane, and (c) the F127 modified PEI/GA/PSS/PAH/F127 262 membrane. 


\subsection{Membrane separation performance}

265 The F127 modified one-bilayer membrane (PEI/GA/PSS/PAH/F127) shows good 266 separation capability with a $2 \mathrm{~g} / \mathrm{L} \mathrm{NaCl}$ feed solution (pH $5.5-6.0)$ under a crossflow 267 filtration mode (Fig. 5), with an intrinsic membrane permeability of $0.75 \mathrm{~L} / \mathrm{m}^{2}$. h.Bar. The 268 salt rejection and permeate flux are respectively $c a .92 \%$ and $11 \mathrm{~L} / \mathrm{m}^{2} \mathrm{~h}$ at $1.6 \mathrm{MPa}$ 269 operating pressure. As the operating pressure increases to 4.0 $\mathrm{MPa}$, the permeate flux 270 increases almost linearly to $c a .30 \mathrm{~L} / \mathrm{m}^{2} \mathrm{~h}$. Simultaneously, the salt rejection increases to 271 ca. $94 \%$.

272 The effects of the crosslinker GA, polyelectrolytes PSS/PAH and surface modifier F127 273 on the separation performance were also investigated at a uniform operating pressure of $2742.4 \mathrm{MPa}$ (Table 1). The PEI/GA membrane has low salt rejection (ca. 28\%) and relatively 275 high permeate flux (ca. $\left.35 \mathrm{~L} / \mathrm{m}^{2} \mathrm{~h}\right)$, indicative of both the low charge density of this layer 276 (Figure 2a2) at neutral $\mathrm{pH}$ and the potential for defects in this single layer. Moreover, the 277 partial dissolution of the PEI polymer into the feed solution over time made the 278 performance of this membrane unstable. The uncrosslinked PEI/PSS/PAH membrane has 279 higher salt rejection ( $c a .50 \%$ ) indicative of the greater charge density (Figure 2b1) but 280 this is still insufficient to form a useful RO membrane, consistent with our prior work [28]. 281 After the GA is introduced (PEI/GA/PSS/PAH), the salt rejection increases significantly 282 to $c a .93 \%$, but this is accompanied by a drastic loss in permeate flux $\left(c a .3 \mathrm{~L} / \mathrm{m}^{2} \mathrm{~h}\right)$. 283 Interestingly, the subsequent F127 spray step increased the permeate flux to $c a .18 \mathrm{~L} / \mathrm{m}^{2} \mathrm{~h}$, 284 while retaining the salt rejection at almost the same level (ca. $93 \%$ ). In contrast, the 285 commercial SW30HR RO membrane exhibits higher salt rejection (ca.99\%) and permeate 286 flux (ca. $22 \mathrm{~L} / \mathrm{m}^{2} \mathrm{~h}$ ) under the same test conditions. However, a direct comparison to these 287 commercial membranes is inappropriate considering that manufacturers have had the 
opportunity to optimize their production for over 40 years; through the use of surfactants, 289 additives and surface coatings [35-37].

290

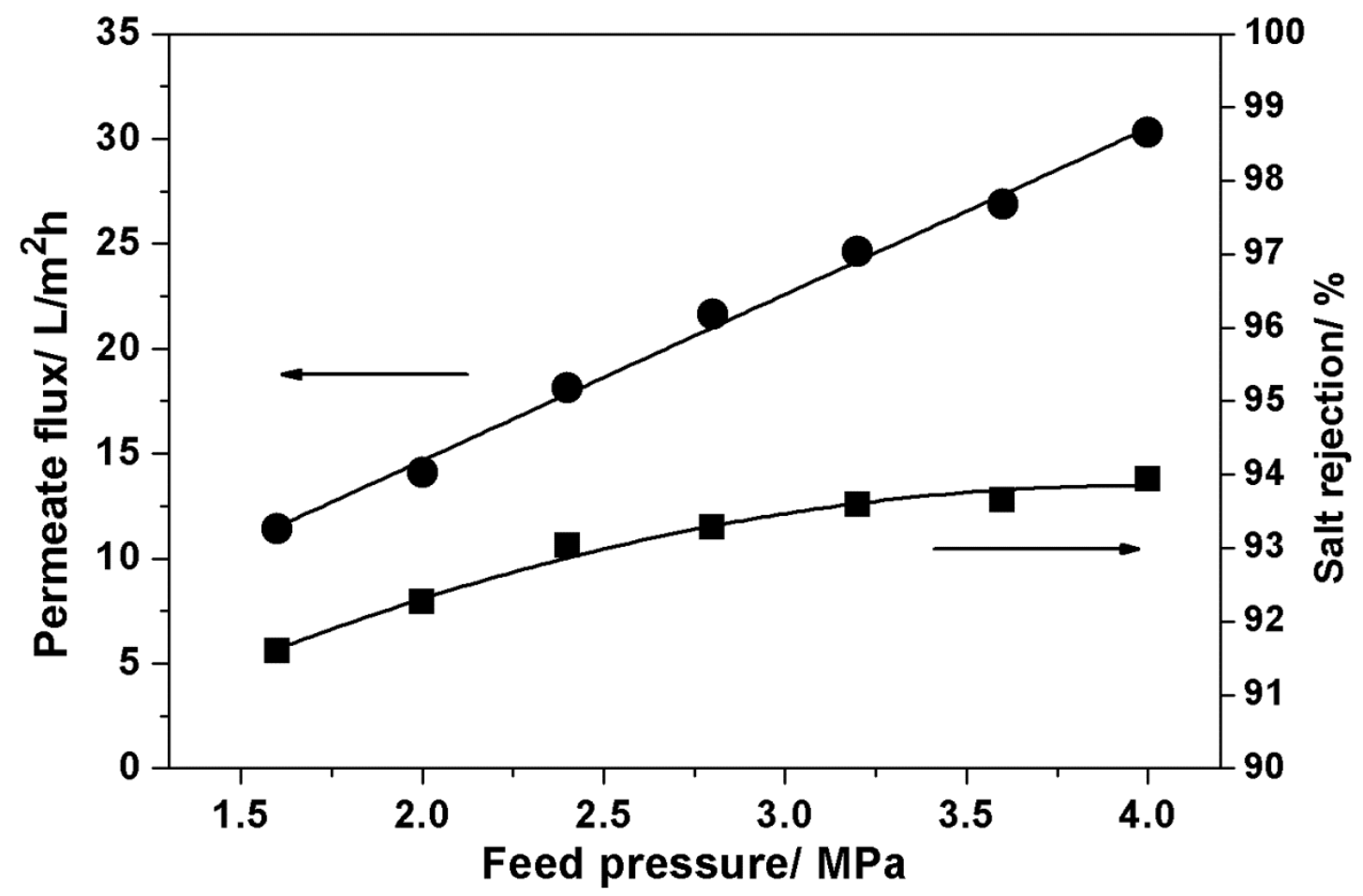

292 Fig. 5. The salt rejection and permeate flux of the F127 modified one-bilayer $293 \mathrm{PEI} / \mathrm{GA} / \mathrm{PSS} / \mathrm{PAH} / \mathrm{F} 127$ membrane versus feed pressures ranging from 1.6 MPa to 4.0 $294 \mathrm{MPa}$ using a $2 \mathrm{~g} / \mathrm{L} \mathrm{NaCl}$ aqueous solution as feed.

295

The boron rejection of the membranes were tested using $20 \mathrm{mg} / \mathrm{L}$ boric acid at $2.4 \mathrm{MPa}$ 297 feed pressure. The results show that both the unmodified PEI/GA/PSS/PAH (ca. 88 \%) and 298 modified PEI/GA/PSS/PAH/F127 (ca. 84 \%) membranes exhibit high boron rejection 299 under basic ( $\mathrm{pH} \mathrm{11)} \mathrm{feed} \mathrm{conditions} \mathrm{where} \mathrm{the} \mathrm{boric} \mathrm{acid} \mathrm{is} \mathrm{charged}[38,39]$. Thus, both 300 membranes are sufficiently negatively charged (Fig. 2b) to reject the small borate anion. 301 However, when the $\mathrm{pH}$ of the feed solution is adjusted to 4 , the PEI/GA/PSS/PAH 
membrane still shows high boron rejection (ca. $87 \%$ ), while the rejection of the PEI/GA/PSS/PAH/F127 membrane falls drastically to $c a .33 \%$. Under these conditions

304

305

306

307

308

309

310

\begin{tabular}{ccc}
\hline Membrane type & Salt rejection/ \% & Permeate flux/ L/m ${ }^{2} \mathrm{~h}$ \\
\hline PEI/GA & $28 \pm 2$ & $35 \pm 3$ \\
PEI/PSS/PAH & $50 \pm 3$ & $24 \pm 4$ \\
PEI/GA/PSS/PAH & $93 \pm 2$ & $3 \pm 1$ \\
PEI/GA/PSS/PAH/F127 & $93 \pm 2$ & $18 \pm 2$ \\
Commercial SW30HR & $99.4 \pm 0.5$ & $22 \pm 2$ \\
\hline
\end{tabular}

Table 1. Salt rejection and permeate flux of experimental and commercial RO membranes with $2 \mathrm{~g} / \mathrm{L} \mathrm{NaCl}$ feed solution ( $\mathrm{pH} 5.5$ - 6.0) at 2.4 MPa feed pressure.

\subsection{Performance stability and protein fouling resistance}

313 The stability of the PEI/GA/PSS/PAH/F127 membrane was evaluated by continuously 314 operation of the membrane for $32 \mathrm{~h}$. The results (Fig. 6) show that the permeate flux was 315 stable at $18.1 \pm 0.3 \mathrm{~L} / \mathrm{m}^{2} \mathrm{~h}$, and the salt rejection also fluctuated in a very small range (92.9 $316 \pm 0.2 \%$ ). This indicates that the membrane possesses excellent separation performance 317 stability. 


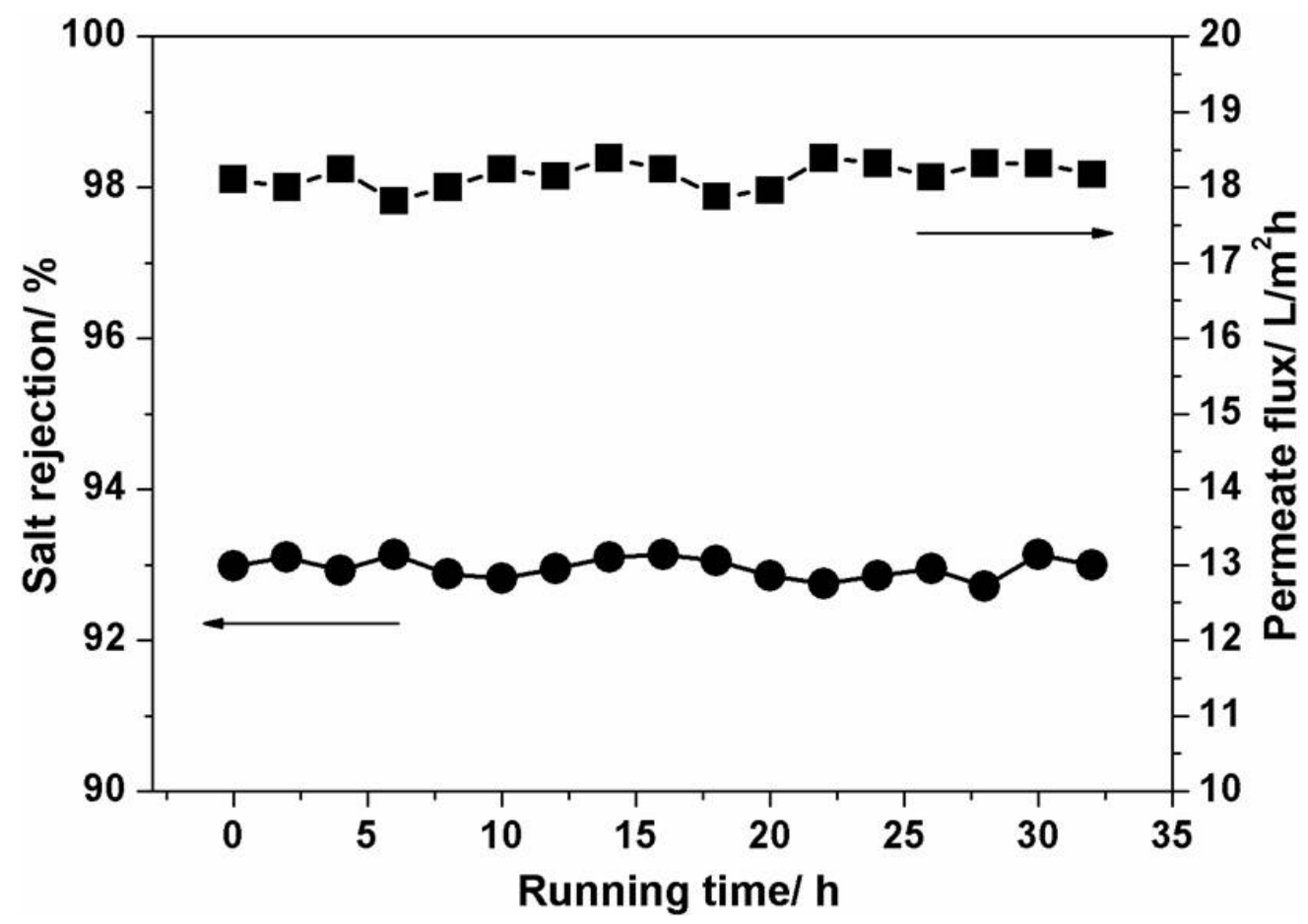

319 Fig. 6. The separation stability of the modified one-bilayer PEI/GA/PSS/PAH/F127

320 membrane over $32 \mathrm{~h}$ of continuous operation with a $2 \mathrm{~g} / \mathrm{L} \mathrm{NaCl}$ aqueous solution and 2.4

321 MPa test pressure.

After filtration with $1 \mathrm{~g} / \mathrm{L}$ BSA solution for $8 \mathrm{~h}$, the normalized permeate flux of the PEI/GA/PSS/PAH/F127 membrane decreased to $c a .74 \%$ of the initial value (Fig. 7a).

325 This flux recovered to $c a .87 \%$ of this value after flushing with water. Conversely, the 326 permeate flux of the unmodified PEI/GA/PSS/PAH membrane decreased further to $c a .68$ $327 \%$ and recovered to $c a .83 \%$ after flushing (Fig. 7b). After fouling for a further two cycles 328 of $8 \mathrm{~h}$ each, the permeate flux of the modified PEI/GA/PSS/PAH/F127 membrane was still $32972 \%$ (Fig. 7a), showing little further loss from the first fouling cycle. Conversely, the 330 normalized permeate flux of the unmodified membrane had decreased to $c a .61 \%$ (Fig. $7 \mathrm{~b}$ ). 331 These results suggest that the F127 surface modification is also favorable for improving 
332 fouling resistance, reflecting the greater hydrophilicity and neutral surface charge of this 333 membrane, which can weaken the interactions with protein foulants [32,34].

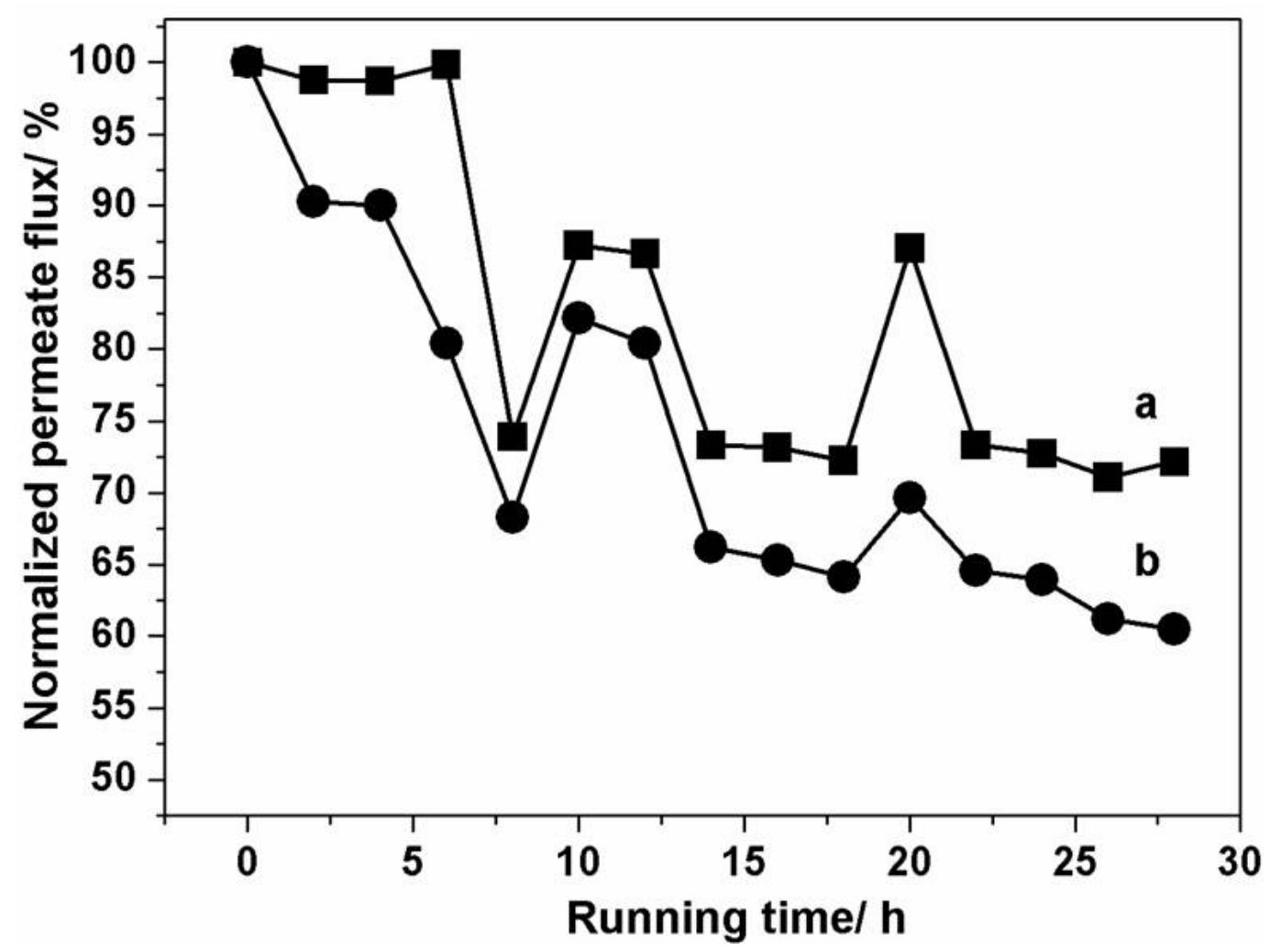

335 Fig. 7. The normalized permeate fluxes of the (a) modified PEI/GA/PSS/PAH/F127 and 336 (b) unmodified PEI/GA/PSS/PAH membranes in $1 \mathrm{~g} / \mathrm{L}$ BSA aqueous solution. The initial 337 fluxes of the PEI/GA/PSS/PAH/F127 and PEI/GA/PSS/PAH membranes are $28 \mathrm{~L} / \mathrm{m}^{2} \mathrm{~h}$ and $3385 \mathrm{~L} / \mathrm{m}^{2} \mathrm{~h}$, respectively.

\subsection{The mechanisms of membrane formation and fouling resistance}

341 In this work, GA is deposited as a crosslinker prior to the addition of PAH. This step

342 plays an important role in improving the polyelectrolyte membrane densification and salt 343 rejection. The GA firstly crosslinks with the amine group of the PEI layer by forming imine 
344 bonds $(-\mathrm{N}=\mathrm{C}-)$ confirmed by the ATR-IR results (Fig. 1). Unreacted aldehyde groups 345 within the GA can further crosslink with the subsequent PAH layer. Relative to our prior 346 work [28], where the 10-bilayer PEI/PSS/PAH membrane was immersed in a GA after the 347 addition of the polyelectrolytes, this makes the PEI layer denser and reduces the defects 348 within the layer (Scheme 1). As a result, this membrane (PEI/GA/PSS/PAH) exhibits a 349 high $\mathrm{NaCl}$ rejection ( $\mathrm{ca} .93 \%$ ), although it only has one polyelectrolyte bilayer. However, 350 the dense, crosslinked active layer simultaneously decreases the diffusion rate of the 351 permeate and the membrane thus possesses very low permeate flux $\left(c a .3 \mathrm{~L} / \mathrm{m}^{2} \mathrm{~h}\right)$. The poor 352 rejection of the uncrosslinked one-bilayer PEI/PSS/PAH membrane ( $c a .50 \%$ ) further 353 confirms the importance of the GA crosslinker for improving salt rejection.

354 After F127 is sprayed onto the surface of the PEI/GA/PSS/PAH membrane, the 355 hydrophobic PPO end partly penetrates into the PAH layer (Scheme 1) by the hydrogen356 bond interactions between the ether groups $\left(-\mathrm{CH}_{2}-\mathrm{O}-\mathrm{CH}_{2}-\right)$ of $\mathrm{F} 127$ and the unreacted 357 amine groups $\left(-\mathrm{NH}_{3}{ }^{+}\right)$of PAH. Correspondingly, the hydrophilicity of the membrane is 358 improved, with the hydrophilic PEO ends directly exposed to the outside in a brush-like 359 structure [20]. This increased hydrophilicity is confirmed by the contact angle results. 360 When the membrane contacts with water in the desalination process, the F127 expands as 361 it absorbs water. This causes the fractional free volume to increase and the formation of 362 water channels between the F127 chains and the PAH layer (Scheme 1). The formation of 363 the new channels and the improvement of surface hydrophilicity confer the one-bilayer $364 \mathrm{PEI} / \mathrm{GA} / \mathrm{PSS} / \mathrm{PAH} / \mathrm{F} 127$ membrane with a higher permeate flux, compared with the 365 unmodified PEI/GA/PSS/PAH membrane.

366 This hypothesis is confirmed by the boron rejection and zeta potential results (Fig. 2) 367 mentioned above. Poly-borate compounds are negligible in concentration at the boron 368 concentrations used $(20 \mathrm{mg} / \mathrm{L})$, and so only boric acid $\left(\mathrm{H}_{3} \mathrm{BO}_{3}\right)$ and borate ions $\left(\mathrm{B}(\mathrm{OH})_{4}^{-}\right)$ 

are present [38]. Boric acid and borate ions have nearly the same Stokes radius (2.6 $\AA$ [38]).

370 Under basic conditions $(\mathrm{pH}=11)$, the boron is present in the form of borate ions $\left(\mathrm{B}(\mathrm{OH})_{4}^{-}\right)$

$371[38,39]$. There is strong charge repulsion between these negatively charged boron ions and 372 the negatively charged surfaces of both the unmodified and the F127 modified one-bilayer 373 membranes (Fig. 2b). The charge repulsion provides both membranes with high boron 374 rejection (ca. $88 \%$ ). After the $\mathrm{pH}$ is adjusted to 4 , boron is mainly present in the form of 375 neutral boric acid $\left(\mathrm{H}_{3} \mathrm{BO}_{3}\right)$ [38,39]. The unmodified PEI/GA/PSS/PAH membrane still 376 shows a higher boron rejection ( $c a .87 \%)$ due to the strong densification of the active layer. 377 However, because the active layer of the F127 modified membrane $378(\mathrm{PEI} / \mathrm{GA} / \mathrm{PSS} / \mathrm{PAH} / \mathrm{F} 127)$ is swollen and charge repulsion disappears, the boric acid 379 species can readily pass through the active layer. Therefore, the modified $380 \mathrm{PEI} / \mathrm{GA} / \mathrm{PSS} / \mathrm{PAH} / \mathrm{F} 127$ membrane possesses a poor boron rejection (ca. 33\%). The 381 change in boron rejection at different $\mathrm{pH}$ values confirms the presence of new water 382 channels in the modified $\mathrm{PEI} / \mathrm{GA} / \mathrm{PSS} / \mathrm{PAH} / \mathrm{F} 127$ membrane. It is noteworthy that 383 although the surface of the modified membrane (PEI/GA/PSS/PAH/F127) is close to its 384 isoelectric point at neutral pH (Fig. 2b), there is clearly sufficient charge within the 385 underlying layers of the membrane itself to provide strong rejection of charged $\mathrm{Na}^{+}$and $\mathrm{Cl}^{-}$ 386 ions, as shown in Table 1.

387 Moreover, the hydrophobic PPO end of the F127 modifier partly penetrates into the 388 PAH layer (Scheme 1), and the hydrophilic PEO end is directly exposed to the outside, 389 forming a "brush-like" structure on the membrane surface [33]. Such "brush-like" PEO 390 structures have been shown by other workers to provide fouling resistance [40-42]. We 391 believe this is the case for the modified PEI/GA/PSS/PAH/F127 membrane as shown in 392 Fig. 6. 


\section{Conclusions}

395 A single bilayer polyelectrolyte RO membrane with high salt rejection and permeate flux 396 has been successfully fabricated by a spray-LBL method using PEI as an adhesion 397 promoter, PSS and PAH as polyanion and polycation, GA as a polyelectrolyte crosslinker, 398 and Pluronic F127 as a surface modifier. The GA crosslinker plays an important role in 399 improving the salt rejection by increasing the membrane densification via forming imine 400 bonds $(-\mathrm{C}=\mathrm{N}-)$ within the PEI layer and PEI/PAH interlayer. It restricts the mobility and 401 conformation change of the polyelectrolyte chains, stabilizing the membrane separation 402 performance. The swelling of the F127 in aqueous solution results in the formation of 403 additional free volume for water permeation within the active layer. The deposited F127 404 also improves the membrane hydrophilicity. These factors confer the membrane with a 405 high permeate flux and improved fouling resistance. Importantly, the membrane can be 406 assembled in a minimum number of processing steps, which will facilitate manufacturing 407 operations at large scale.

\section{Acknowledgments}

410 Qiang Li acknowledges the financial support from the China Scholarship Council (CSC) 411 (No. 201504180033), the National Natural Science Foundation of China (NSFC) (No. 412 21406041), the special financial fund support from the Public Welfare Project of the 413 Marine Industry (No. 201405009-3) and the Project of Scientific \&Technology Support of 414 the 12th Five-year Plan of China (No. 2014BAB06B00) and the support from The 415 University of Melbourne. 


\section{References}

419 [1] M.T.M. Pendergast, E.M.V. Hoek, A review of water treatment membrane 420 nanotechnologies, Energy Environ. Sci. 4 (2011) 1946-1971.

421 [2] G.-R. Xu, S.-H. Wang, H.-L. Zhao, S.-B. Wu, J.-M. Xu, L. Li, X.-Y. Liu, Layer-by422 layer (LBL) assembly technology as promising strategy for tailoring pressure-driven 423 desalination membranes, J. Membr. Sci. 493 (2015) 428-443.

424 [3] A. Pérez-González, A.M. Urtiaga, R. Ibáñez, I. Ortiz, State of the art and review on the 425 treatment technologies of water reverse osmosis concentrates, Water Res. 46 (2012) 267426283.

427 [4] Q. Li, J. Song, H. Yu, Z. Li, X. Pan, B. Yang, Investigating the microstructures and 428 surface features of seawater RO membranes and the dependencies of fouling resistance 429 performances, Desalination 352 (2014) 109-117.

430 [5] G. Decher, J.D. Hong, J. Schmitt, Buildup of ultrathin multilayer films by a self431 assembly process: III. consecutively alternating adsorption of anionic and cationic 432 polyelectrolytes on charged surfaces, Thin Solid Films 210 (1992) 831-835.

433 [6] G. Decher, Fuzzy nanoassemblies: toward layered polymeric multicomposites, Science 434277 (1997) 1232-1237.

435 [7] J.J. Richardson, M. Björnmalm, F. Caruso, Technology-driven layer-by-layer assembly 436 of nanofilms, Science 348 (2015) 2491-2501.

437 [8] P. Schaaf, J.-C. Voegel, L. Jierry, F. Boulmedais, Spray-assisted polyelectrolyte 438 multilayer buildup: from step-by-step to single-step polyelectrolyte film constructions, 439 Adv. Mater. 24 (2012) 1001-1016. 
440 [9] R. Blell, X. Lin, T. Lindstr $\square$ m, M. Ankerfors, M. Pauly, O. Felix, G. Decher, 441 Generating in-plane orientational order in multilayer films prepared by spray-assisted 442 layer-by-layer assembly, ACS Nano 11 (2017) 84-94.

443 [10] A. Gopalakrishnan, M.L. Mathew, J. Chandran, J. Winglee, A.R. Badireddy, M. 444 Wiesner, C.T. Aravindakumar, U.K. Aravind, Sustainable polyelectrolyte multilayer 445 surfaces: possible matrix for salt/dye separation, ACS Appl. Mater. Interfaces, 7 (2015) $446 \quad 3699-3707$.

447 [11] J. Borges, J.F. Mano, Molecular interactions driving the layer-by-layer assembly of 448 multilayers, Chem.Rev. 114 (2014) 8883-8942.

449 [12] H. Zhen, T. Wang, R. Jia, B. Su, C. Gao, Preparation and performance of antibacterial 450 layer-by-layer polyelectrolyte nanofiltration membranes based on metal-ligand 451 coordination interactions, RSC Adv. 5 (2015) 86784-86794.

452 [13] X. Zhang, H. Chen, H. Zhang, Layer-by-layer assembly: From conventional to 453 unconventional methods, Chem. Commun. (2007) 1395-1405.

454 [14] L.Y. Ng, A.W. Mohammad, C.Y. Yin, A review on nanofiltration membrane 455 fabrication and modification using polyelectrolytes: Effective ways to develop membrane 456 selective barriers and rejection capability, Adv. Colloid Interface Sci. 197-198 (2013) 85457107.

458 [15] B. Su, T. Wang, Z. Wang, X. Gao, C. Gao, Preparation and performance of dynamic 459 layer-by-layer PDADMAC/PSS nanofiltration membrane, J. Membr. Sci. 423 (2012) $460 \quad 324-331$. 
461 [16] J. Meier-Haack, W. Lenk, D. Lehmann, K. Lunkwitz, Pervaporation separation of 462 water/alcohol mixtures using composite membranes based on polyelectrolyte multilayer 463 assemblies, J. Membr. Sci. 184 (2001) 233-243.

464 [17] C. Qiu, S. Qi, C.Y. Tang, Synthesis of high flux forward osmosis membranes by 465 chemically crosslinked layer-by-layer polyelectrolytes, J. Membr. Sci. 381 (2011) 74-80.

466 [18] D. Saeki, M. Imanishi, Y. Ohmukai, T. Maruyama, H. Matsuyama, Stabilization of 467 layer-by-layer assembled nanofiltration membranes by crosslinking via amide bond 468 formation and siloxane bond formation, J. Membr. Sci. 447 (2013), 128-133.

469 [19] J. Grooth, R. Oborný, J. Potreck, K. Nijmeijer, W.M. Vos, The role of ionic strength 470 and odd-even effects on the properties of polyelectrolyte multilayer nanofiltration 471 membranes, J. Membr. Sci. 475 (2015) 311-319.

472 [20] T. Wang, J. Lu, L. Mao , Z. Wang, Electric field assisted layer-by-layer assembly of 473 grapheme oxide containing nanofiltration membrane, J. Membr. Sci. 515 (2016) 125-133.

474 [21] J. Park, J. Park, S.H. Kim, J. Cho, J. Bang, Desalination membranes from pH475 controlled and thermally-crosslinked layer-by-layer assembled multilayers, J. Mater. 476 Chem. 20 (2010) 2085-2091.

477 [22] P.H.H. Duong, J. Zuo, T.-S. Chung, Highly crosslinked layer-by-layer polyelec478 trolyte FO membranes: Understanding effects of salt concentration and deposition time on 479 FO performance, J. Membr. Sci. 427 (2013) 411-421.

480 [23] K.L. Cho, H. Lomas, A.J. Hill, F. Caruso, S.E. Kentish, Spray assembled, cross-linked 481 polyelectrolyte multilayer membranes for salt removal, Langmuir 30 (2014) 8784-8790. 
482 [24] H. Tang, G. Zhang, S. Ji, Rapid assembly of polyelectrolyte multilayer membranes 483 using an automatic spray system, AIChE J. 59 (2013) 250-257.

484 [25] A. Toutianoush, L. Krasemann, B. Tieke, Polyelectrolyte multilayer membranes for 485 pervaporation separation of alcohol/water mixtures, Colloids Surfaces A Physicochem. 486 Eng. Asp. 198 (2002) 881-889.

487 [26] J.B. Schlenoff, S.T. Dubas, T. Farhat, Sprayed polyelectrolyte multilayers, Langmuir $488 \quad 16(2000) 9968-9969$.

489 [27] H. Tang, S. Ji, L. Gong, H. Guo, G. Zhang, Tubular ceramic-based multilayer 490 separation membranes using spray layer-by-layer assembly, Polym. Chem. 4 (2013) $491 \quad 5621-5628$.

492 [28] K.L. Cho, A. J. Hill, F. Caruso, S.E. Kentish, Chlorine resistant glutaraldehyde 493 crosslinked polyelectrolyte multilayer membranes for desalination, Adv. Mater. 27 (2015) $494 \quad 2791-2796$.

495 [29] Y.-N. Kwon, S. Hong, H. Choi, T. Tak, Surface modification of a polyamide reverse 496 osmosis membrane for chlorine resistance improvement, J. Membr. Sci. 415 (2012) 192$497 \quad 198$.

498 [30] W. Choi, J. Choi, J. Bang, J.-H. Lee, Layer-by-layer assembly of graphene oxide 499 nanosheets on polyamide membranes for durable reverse-osmosis applications, ACS 500 Appl. Mater. Interfaces 5 (2013) 12510-12519.

501 [31] Y. Jin, Y. Hua, P. Zhang, Y. Yun, P. Zhang, C. Li, Preparation and characterization 502 of poly(vinylidene fluoride) ultrafiltration membrane with organic and inorganic porogens, 503 Desalination $336(2014) 1-7$. 
504 [32] Y. Zhang, Y. Su, W. Chen, J. Peng, Y. Dong, Z. Jiang, H. Liu, Appearance of 505 poly(ethylene oxide) segments in the polyamide layer for antifouling nanofiltration 506 membranes, J. Membr. Sci. 382 (2011) 300-307.

507 [33] C.H. Loh, R. Wang, L. Shi, A.G. Fane, Fabrication of high performance 508 polyethersulfone UF hollow fiber membranes using amphiphilic pluronic block 509 copolymers as pore-forming additives, J. Membr. Sci. 380 (2011) 114-123.

510 [34] W. Falath, A. Sabir, K.I. Jacob, Novel reverse osmosis membranes composed of 511 modified PVA/gum arabic conjugates: Biofouling mitigation and chlorine resistance 512 enhancement, Carbohyd. Polym. 155 (2017) 28-39.

513 [35] W.J. Lau, A.F. Ismail, N. Misdan, M.A. Kassim, A recent progress in thin film 514 composite membrane: A review, Desalination, 287 (2012) 190-199.

515 [36] C.Y. Tang, Y.-N. Kwon, J.O. Leckie, Probing the nano- and micro-scales of reverse 516 osmosis membranes-A comprehensive characterization of physiochemical properties of 517 uncoated and coated membranes by XPS, TEM, ATR-FTIR, and streaming potential 518 measurements, Journal of Membrane Science, 287 (2007) 146-156.

519 [37] A. Widjaya, T. Hoang, G.W. Stevens, S.E. Kentish, A comparison of commercial 520 reverse osmosis membrane characteristics and performance under alginate fouling 521 conditions, Separation and Purification Technology, 89 (2012) 270-281.

522 [38] K. Kezia, J. Lee, A. J. Hill, S.E. Kentish, Convective transport of boron through a 523 brackish water reverse osmosis membrane, J. Membr. Sci. 445 (2013)160-169.

524 [39] D. David, H. Ingemar, Research paper: Ionic medium effects in sea water-a 525 comparison of acidity constants of carbonic acid and boric acid in sodium chloride and 526 synthetic sea water, Mar. Chem. 1 (1973) 137-149. 
527 [40] G. Kaltali, H. Kalipcilar, P.Z. Culfaz-Emecen, Effect of three different PEO528 containing additives on the fouling behavior of PES-based ultrafiltration membranes, Sep. 529 Purificat. Technol. 150 (2015) 21-28

530 [41] A. Asatekin, S. Kang, M. Elimelech, A.M. Mayes, Anti-fouling ultrafiltration 531 membranes containing polyacrylonitrile-graft-poly (ethylene oxide) comb copolymer 532 additives, J. Membr. Sci. 298 (2007) 136-146.

533 [42] F. Liu, C.-H. Du, B.-K. Zhu, Y.-Y. Xu, Surface immobilization of polymer brushes 534 onto porous poly(vinylidene fluoride) membrane by electron beam to improve the 535 hydrophilicity and fouling resistance, Polymer 48 (2007) 2910-2918.

536

537

538 
Supporting Information

\title{
Spray Assisted Layer-by-Layer Assembled One-Bilayer Polyelectrolyte Reverse Osmosis Membranes
}

\author{
Qiang Li, ${ }^{a}$ George Q. Chen, ${ }^{b}$ Liang Liu, ${ }^{\mathrm{b}}$ and Sandra E. Kentish ${ }^{* b}$
}

${ }^{a}$ The Institute of Seawater Desalination and Multipurpose Utilization, SOA (Tianjin), Tianjin 300192, China

${ }^{b}$ Department of Chemical Engineering, The University of Melbourne, VIC 3010, Australia

*Corresponding Author E-mail: sandraek@unimelb.edu.au (S. E. Kentish). 


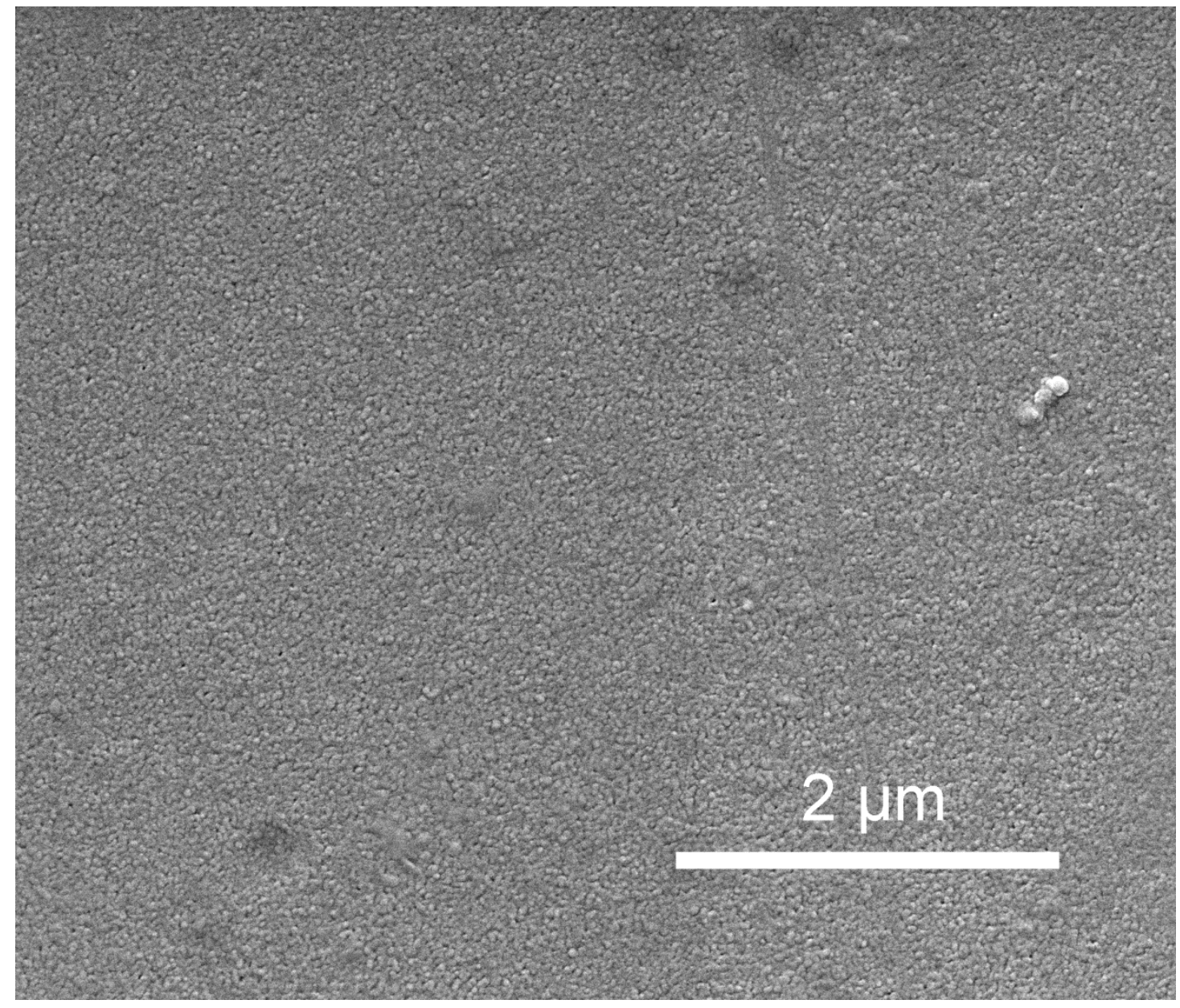

Fig. S1. SEM images of the top surface of the PSF substrate. 


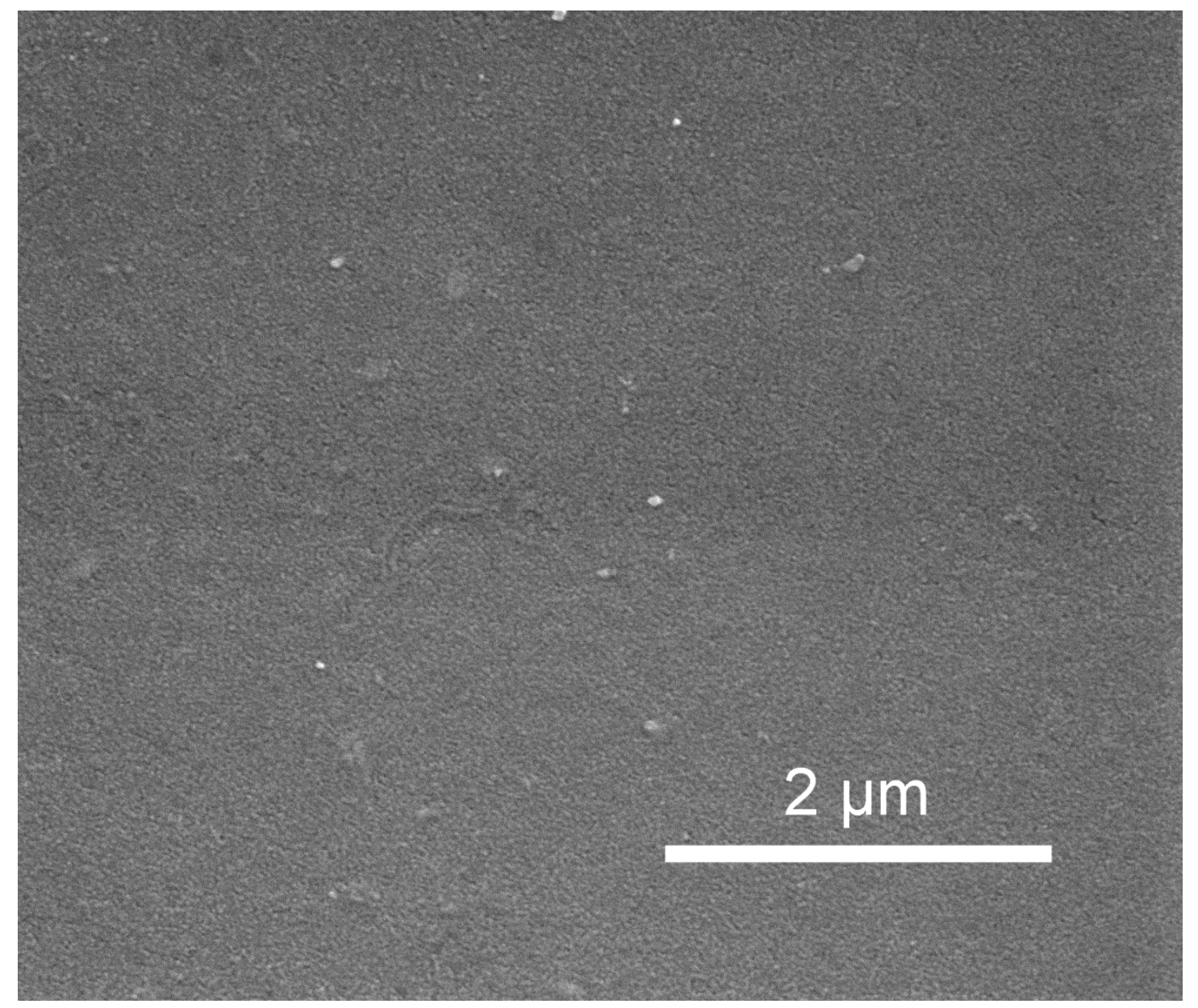

Fig. S2. SEM image of the top surface of the modified PEI/GA/PSS/PAH/F 127 membrane. 


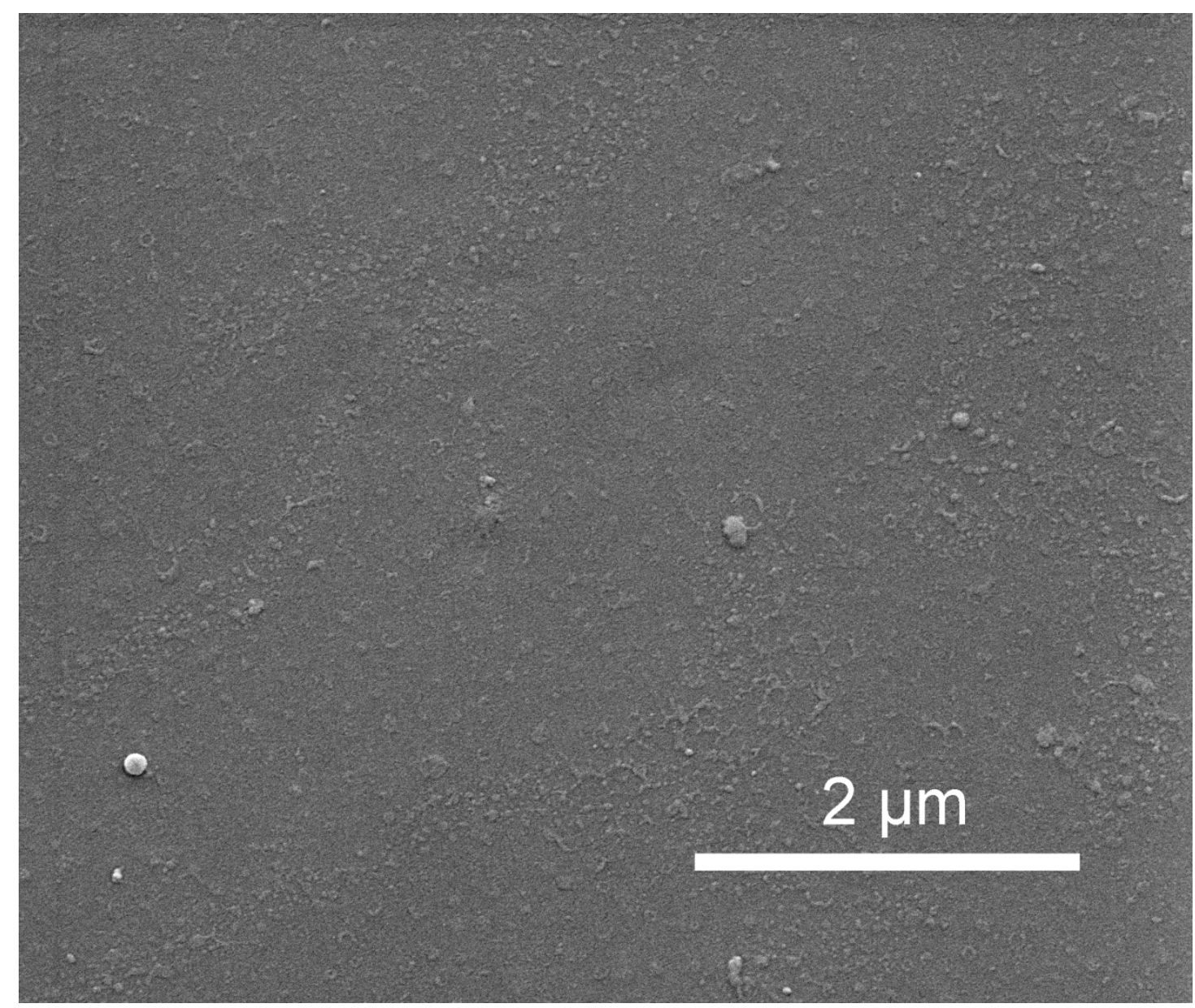

Fig. S3. SEM image of the top surface of the unmodified PEI/GA/PSS/PAH membrane 


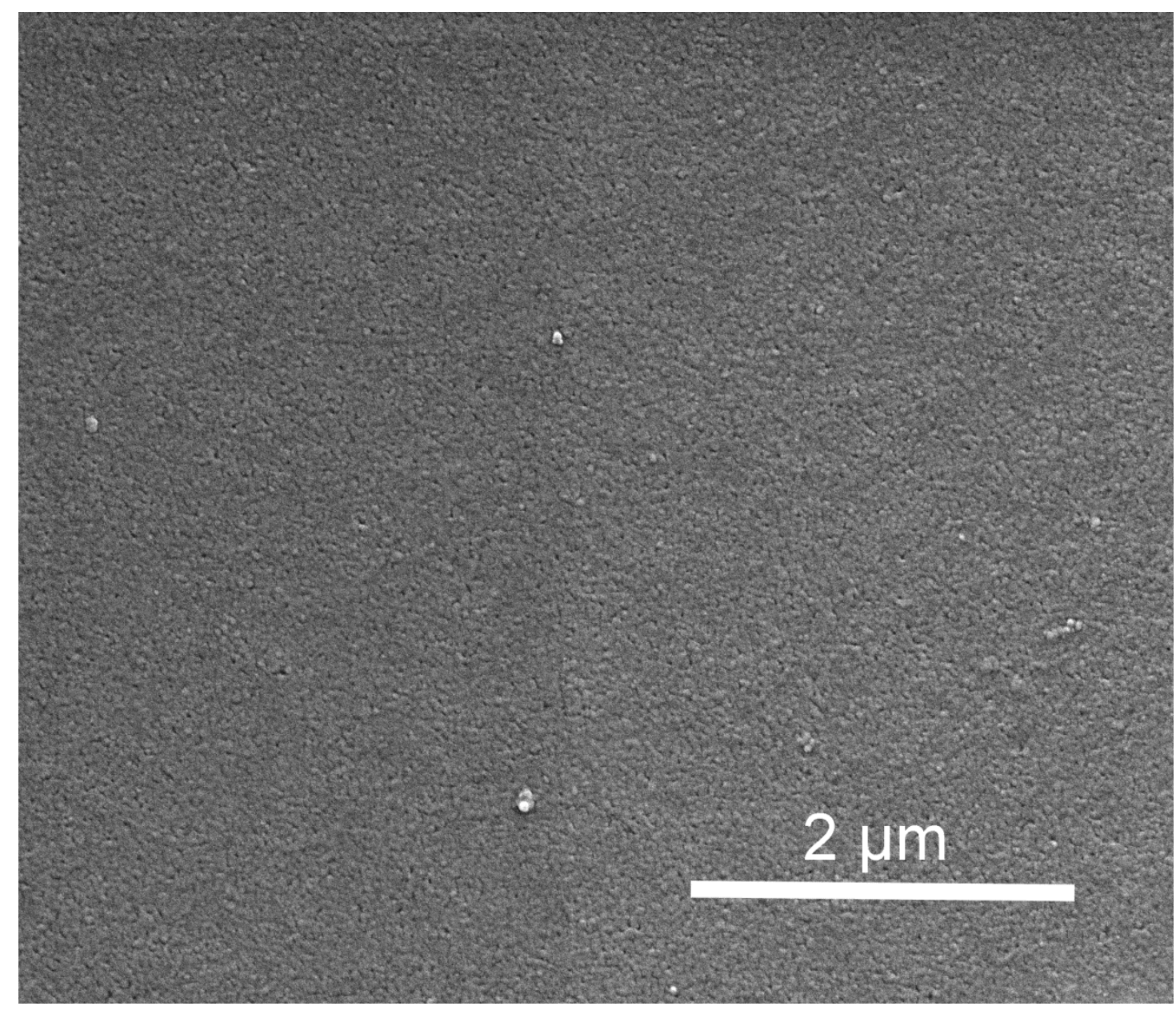

Fig. S4. SEM images of the top surfaces of the uncrosslinked PEI/PSS/PAH membrane. 


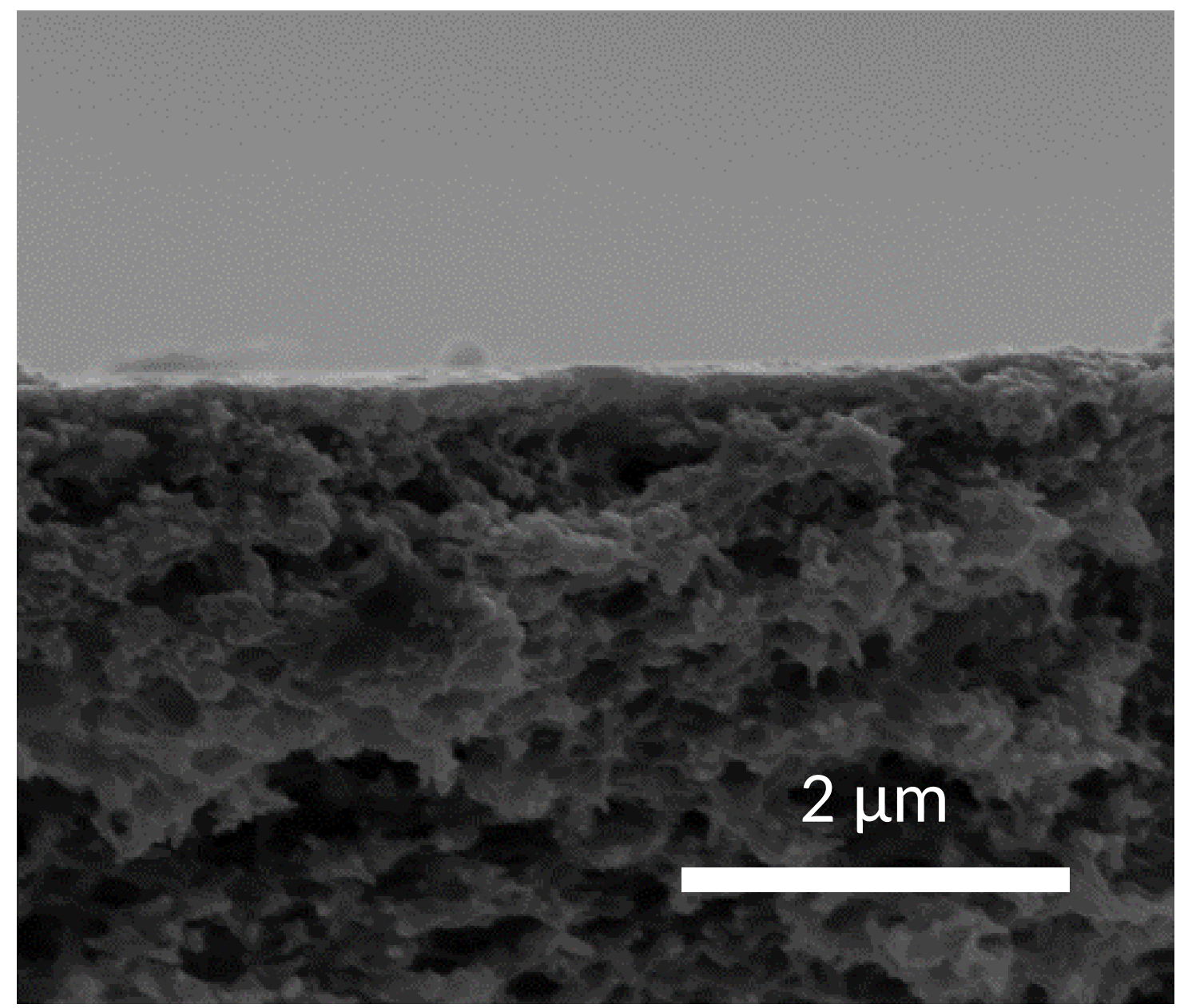

Fig. S5. SEM image of the cross section of the PSF substrate. 


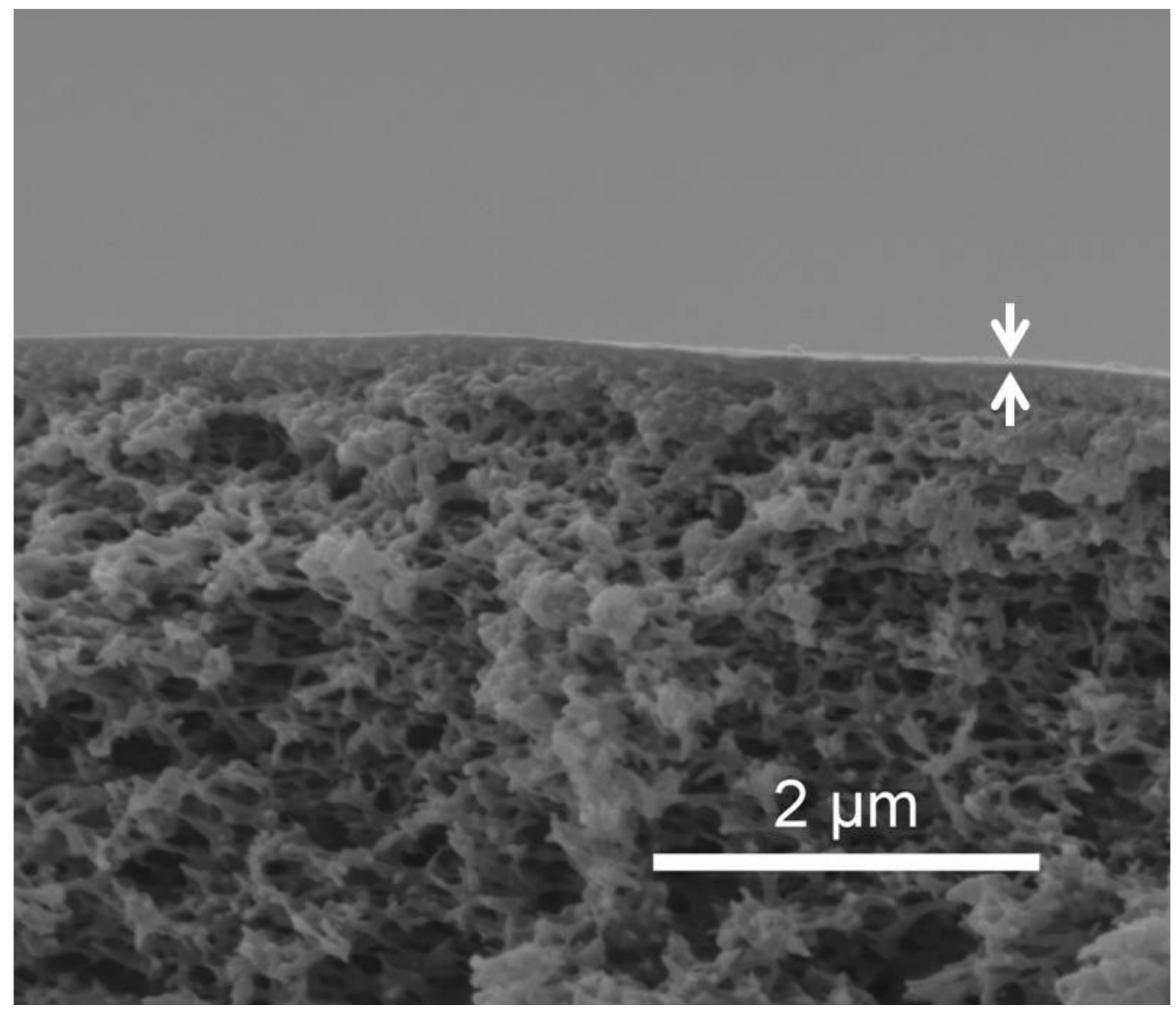

Fig. S6. SEM image of the cross section of the unmodified PEI/GA/PSS/PAH membrane. 


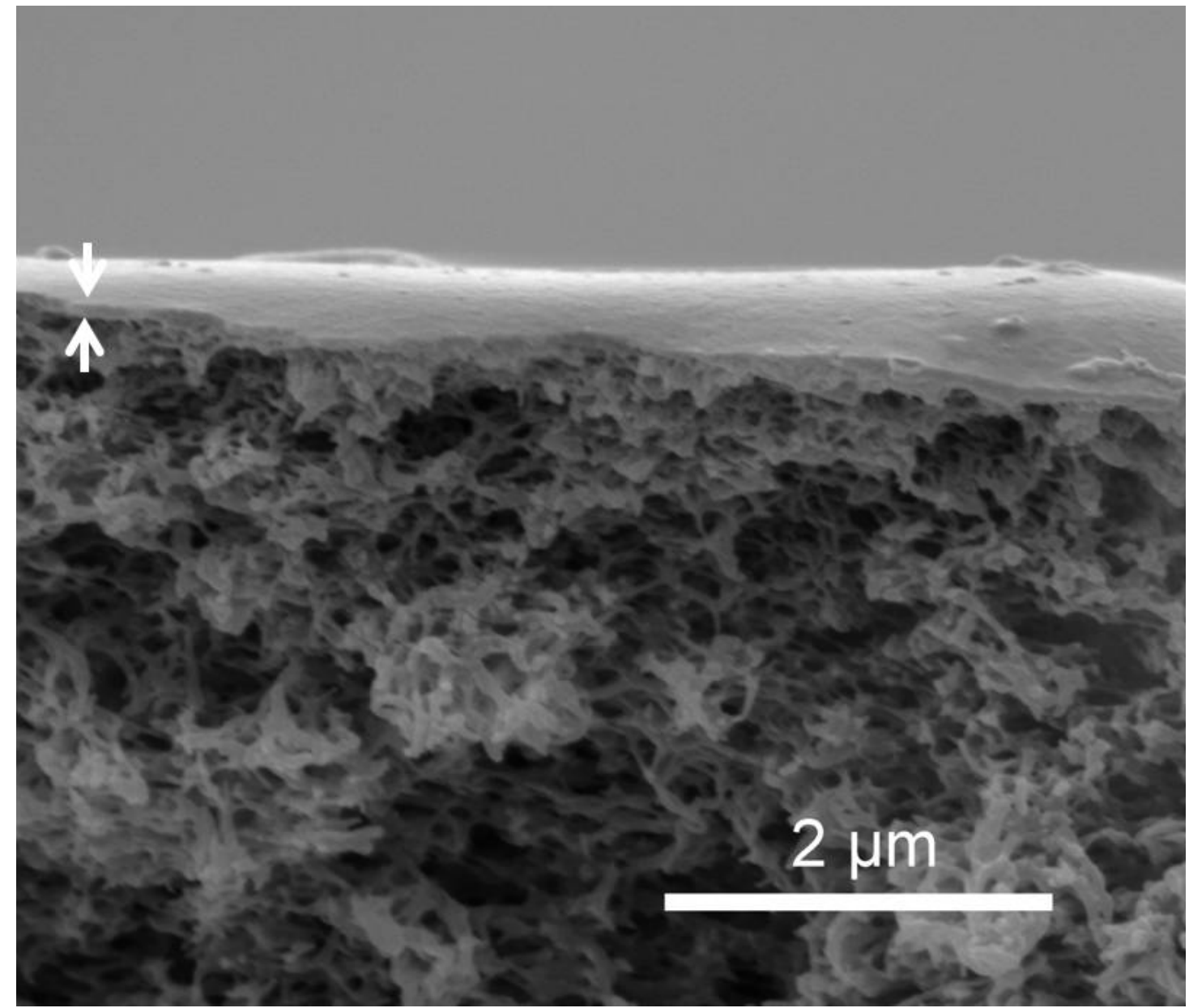

Fig. S7. SEM image of the cross section of the F127 modified PEI/GA/PSS/PAH/F127 membrane. 